\title{
Endoscopic therapy of oesophageal strictures in children - a multicentre study
}

\author{
Stanisław Pieczarkowski ${ }^{1}$, Marek Woynarowski ${ }^{2}$, Piotr Landowski ${ }^{3}$, Robert Wilk ${ }^{4}$, Adam Daukszewicz $^{5}$, \\ Ewa Toporowska-Kowalska ${ }^{6}$, Piotr Albrecht ${ }^{7}$, Iwona Ignys ${ }^{8}$, Elżbieta Czkwianianc ${ }^{9}$, Elżbieta Jarocka-Cyrta ${ }^{10}$, \\ Bartosz Korczowski ${ }^{11}$
}

\author{
${ }^{1}$ Department of Paediatrics, Gastroenterology, and Nutrition, Polish-American Children's Hospital, Jagiellonian University \\ Medical College, Krakow, Poland \\ 2Department of Gastroenterology, Hepatology, and Immunology, Children's Memorial Health Institute, Warsaw, Poland \\ ${ }^{3}$ Chair and Department of Paediatrics, Gastroenterology, Hepatology, and Paediatric Nutrition, Medical University of Gdansk, \\ Gdansk, Poland \\ ${ }^{4}$ Department of Paediatric Surgery, Polish-American Children's Hospital, Jagiellonian University Medical College, Krakow, Poland \\ ${ }^{5}$ The Regional Children's Specialised Hospital, Olsztyn, Poland \\ ${ }^{6}$ Department of Paediatric Gastroenterology and Allergy, Medical University of Lodz, Lodz, Poland \\ ${ }^{7}$ Department of Gastroenterology and Paediatric Nutrition, Medical University of Warsaw, Warsaw, Poland \\ ${ }^{8}$ Department of Paediatric Gastroenterology and Metabolic Diseases, Poznan University of Medical Sciences, Poznan, Poland \\ ${ }^{9}$ Department of Gastroenterology and Paediatrics, Polish Mother's Memorial Hospital - Research Institute, Lodz, Poland \\ ${ }^{10}$ Department of Paediatrics, Gastroenterologu and Nutrition, Faculty of Medical Science University of Warmia and Mazury, \\ Olsztyn, Poland \\ ${ }^{11}$ Department of Pediatric Gastroenterology, University of Rzeszow, Rzeszow, Poland
}

Key words: children, oesophageal stenosis, dilatation.

Address for correspondence: Stanisław Pieczarkowski MD, PhD, Department of Paediatrics, Gastroenterology, and Nutrition, Polish-American Children's Hospital Jagiellonian University Medical College, 265 Wielicka St, 30-009 Krakow, Poland, phone: +48 602402 131, e-mail: stpiecz@wp.pl

\begin{abstract}
Introduction: Oesophageal strictures are rare in children but may require endoscopic dilation.

Aim: To gather information on centres performing endoscopic oesophageal dilation in Poland.

Material and methods: The data were obtained from questionnaires concerning the relevant data mailed to 22 paediatric endoscopy centres. Completed questionnaires were received from 11 centres.

Results: In 2010 the 11 Polish paediatric endoscopy centres performed a total of 10,650 endoscopic procedures. This included 347 oesophageal dilations in 106 paediatric patients aged from 1 month to 18 years. The numbers of patients treated at individual centres ranged from 2 to 40 . The indications for oesophageal dilation were as follows: postoperative strictures in 68 children, oesophageal burns in 17 children, postinflammatory strictures in 14 children, achalasia in 4 children, and strictures caused by a foreign body in 3 children. Rigid guidewire dilators were used in the majority of procedures (271), rigid dilators without a guidewire in 32 procedures, and balloon dilators in 45 procedures. A total of 203 procedures were conducted under fluoroscopic guidance, and 144 without the use of fluoroscopy. The number of dilating sessions performed in individual children varied from 1 to 6 and more.

Conclusions: Oesophageal dilation constituted a minor proportion of all paediatric endoscopic procedures. The majority of children requiring dilation were patients up to 3 years of age with postoperative oesophageal strictures. In the majority of the centres rigid guidewire dilators were used, and in one third of the procedures these dilators were introduced without fluoroscopic guidance.
\end{abstract}

\section{Introduction}

The typical aetiology of oesophageal strictures is different in children and in adults. In adults the most common cause of strictures are oesophageal neoplasms, while in children the most common causes are complications of surgical treatment of oesophageal atresia, or oesophageal burns due to ingestion of caustic substances. Regardless of the aetiology, oesophageal 
strictures cause impairment of oral feeding and may lead to cachexia in adults or failure to thrive in children. Therefore, oesophageal strictures require treatment to achieve oesophageal patency that is sufficient for oral feeding and to maintain the highest possible quality of life. Endoscopic oesophageal dilation is the treatment of choice. In patients in whom the results of such treatment are unsatisfactory, surgical repair is performed.

\section{Aim}

There is no universally accepted standard of endoscopic treatment of patients with oesophageal strictures. The numbers of Polish centres that perform this type of procedures, as well as the number of procedures performed in Poland, is not known. The aim of our study was to collect information on the centres capable of endoscopic oesophageal dilation, the numbers of patients who require such treatment, as well as the number of performed procedures, and their techniques and complications.

\section{Material and methods}

The survey included paediatric gastroenterology centres capable of diagnostic and therapeutic endoscopy in children. The study questionnaire was mailed to all such centres. It contained questions concerning:

1. Characteristics of the centre and its endoscopic unit(s): number of gastroenterologists and surgeons performing endoscopic procedures, equipment of the endoscopy unit(s), availability of radiological equipment, and feasibility of general anaesthesia at the unit(s).

2. Number of endoscopic procedures performed in 2010.

3. Number of patients requiring oesophageal dilation and their characteristics (age, aetiology of the strictures).

4. Techniques used for oesophageal dilation (including the types of dilators, use of guidewires, fluoroscopic guidance, and type of anaesthesia).

5. Complications of oesophageal dilation.
The questionnaires were mailed to 22 Polish paediatric endoscopy centres; 11 of the centres responded.

\section{Results}

Most frequently (6/11 centres) oesophageal dilation was performed at an endoscopy unit affiliated with a paediatric department, or less commonly (2/11) with a surgical department, or at an independent adult endoscopy unit (2/11), and least frequently (1/11) at an independent paediatric endoscopy unit (Figure 1).

At the majority of the centres (8/11) only one endoscopy unit was available, and $3 / 11$ centres had two or more units. In 8/11 centres analgesia was possible on site, while in the remaining $3 / 11$ centres it had to be performed in the operation room.

Only at one centre was radiographic equipment (C arm) available in the endoscopy unit. In the remaining 10 centres the procedures requiring fluoroscopy were performed in a radiology department.

In the 11 paediatric endoscopy centres in Poland, gastrointestinal endoscopic procedures, including oesophageal dilation, were performed by a total of 39 physicians, including 21 paediatric gastroenterologists and 12 paediatric surgeons, who used a total of 42 gastroscopes.

In 2010 the centres performed a total of 10,650 endoscopic procedures, including 347 oesophageal dilations (which accounted for approximately $3.5 \%$ of the endoscopic procedures). The number of oesophageal dilations performed annually at individual centres ranged from 2 to 144. A total of 106 children, including 65 boys and 41 girls, aged from several weeks to 18 years, were treated (Figure 2).

In 8 centres the annual numbers of treated patients were in the range of 2 to 6 per centre, and only in 3 centres were they higher, ranging from 11 to 40 patients per centre. Among the 11 centres the experience in endoscopic oesophageal dilation was over 25 years in 2 centres, over 15 years in 4 centres, and over 5 years in 5 centres.

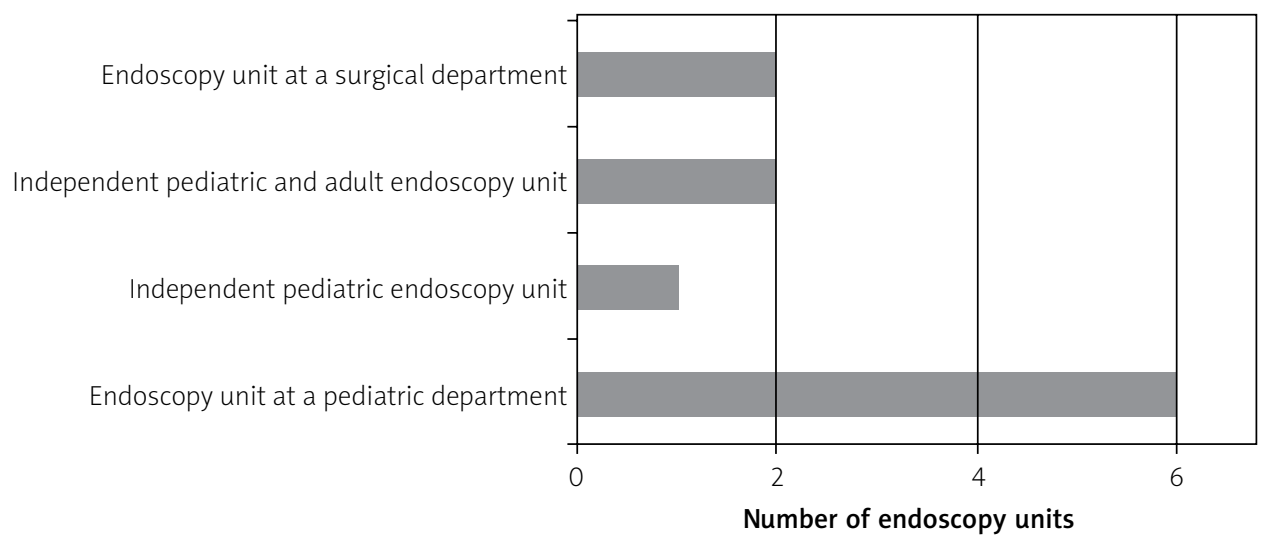

Figure 1. Characteristics of the endoscopy centres 


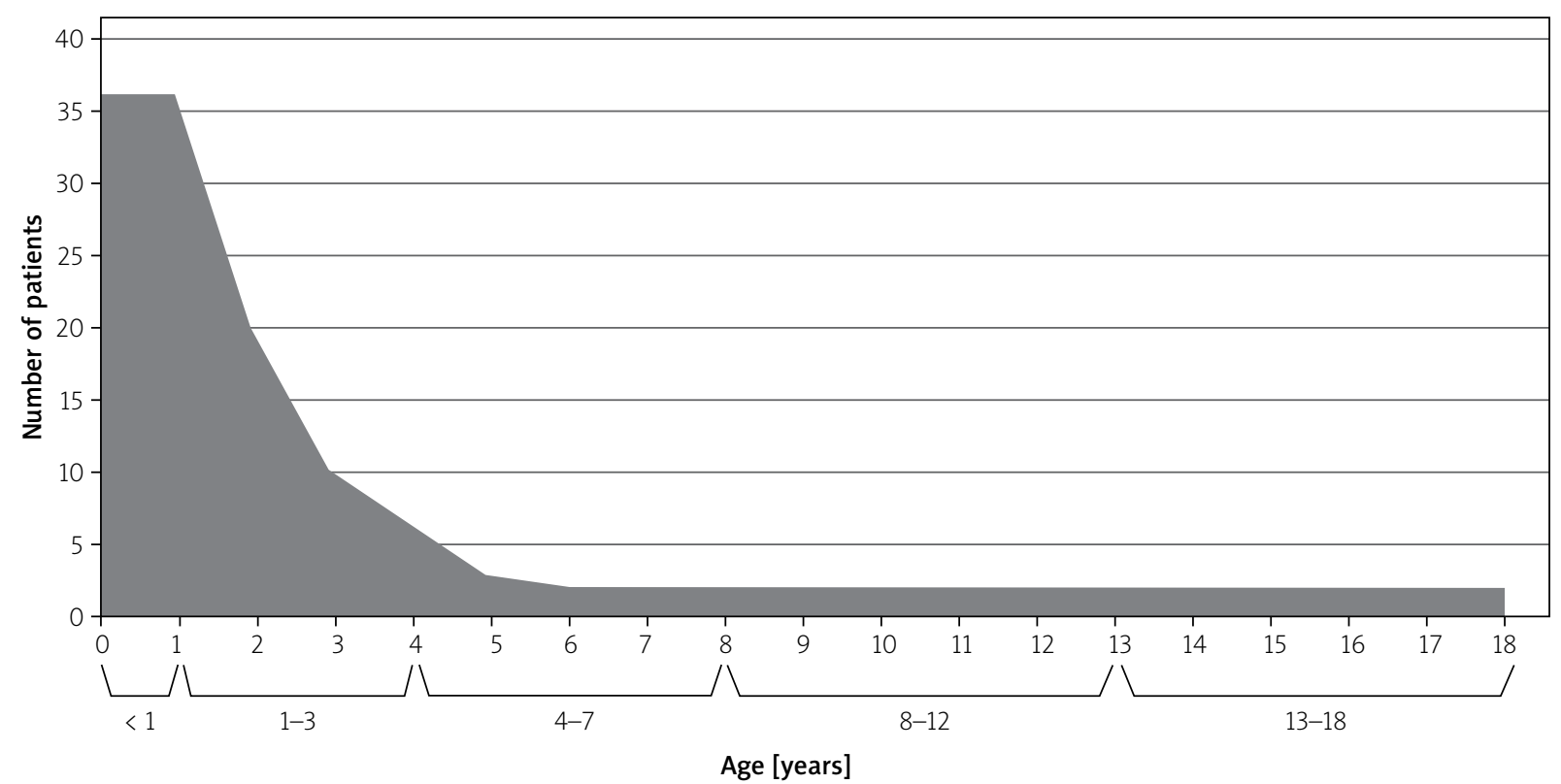

Figure 2. Age distribution of children with oesophageal strictures

The indications for oesophageal dilation were postoperative strictures in 68 children, strictures caused by oesophageal burns in 17 children, postinflammatory strictures in 14 children, achalasia in 4 children, and strictures caused by foreign bodies in 3 children.

The most commonly used technique (8 out of the 11 centres, 271 procedures) of oesophageal dilation was the use of rigid guidewire dilators. Balloon dilators were used in 7 of the 11 centres (45 procedures).
Only 4 centres used rigid dilators without a guidewire (32 procedures) (Table I).

The majority of the procedures (203) were performed under fluoroscopic guidance, and in 144 procedures fluoroscopy was not used.

The number of oesophageal dilations in children ranged from 1 to $>6$ ( 1 in 30 children, 2 in 22 children, 3 in 13 children, 4 in 9 children, 5 in 10 children, 6 in 9 children, and $>6$ in 13 children).

Table I. Techniques of oesophageal dilation

\begin{tabular}{|c|c|c|c|c|c|c|}
\hline \multirow[t]{2}{*}{ No. } & \multirow[t]{2}{*}{ Centre } & \multicolumn{3}{|c|}{ Without fluoroscopy } & \multicolumn{2}{|c|}{ With fluoroscopy } \\
\hline & & $\begin{array}{l}\text { Rigid dilator with } \\
\text { a guidewire }\end{array}$ & $\begin{array}{c}\text { Rigid dilator } \\
\text { without a guidewire }\end{array}$ & Balloon dilator & $\begin{array}{l}\text { Rigid dilator with } \\
\text { a guidewire }\end{array}$ & Balloon dilator \\
\hline 1 & WSSD Olsztyn & 1 & 1 & & 18 & 1 \\
\hline 2 & UM Lodz & 17 & & & & \\
\hline 3 & UM Poznan & & & 9 & & \\
\hline 4 & CZMP Lodz & 3 & & & & \\
\hline 5 & $\begin{array}{l}\text { CZMP Lodz, } \\
\text { Surgical Department }\end{array}$ & 14 & & & 3 & \\
\hline 6 & IP CZD Warsaw & & & & 134 & 10 \\
\hline 7 & UR Rzeszow & & & & 2 & \\
\hline 8 & UM Bialystok & & 8 & & & \\
\hline 9 & WUM Warsaw & & 4 & 14 & 1 & \\
\hline 10 & GUMED Gdansk & 32 & & 5 & 28 & 6 \\
\hline 11 & PAIP Krakow & 18 & 19 & & & \\
\hline
\end{tabular}


Table II. Medical personnel assisting with endoscopic oesophageal dilation and parameters monitored during the procedure

\begin{tabular}{|c|c|c|c|c|c|c|c|}
\hline No. & Centre & Endoscopist & Assistant & Nurse & $\begin{array}{l}\text { Blood } \\
\text { pressure }\end{array}$ & Pulse & $\begin{array}{l}\text { Oxygen } \\
\text { saturation }\end{array}$ \\
\hline 1 & WSSD Olsztyn & Y & N & Y & Y & Y & Y \\
\hline 2 & UM Lodz & Y & N & Y & N & Y & Y \\
\hline 3 & UM Poznan & Y & $\mathrm{N}$ & Y & Y & Y & Y \\
\hline 4 & CZMP Lodz & Y & $\mathrm{N}$ & Y & Y & Y & Y \\
\hline 5 & $\begin{array}{c}\text { CZMP Lodz, } \\
\text { Surgical Department }\end{array}$ & Y & $\mathrm{N}$ & Y & Y & Y & Y \\
\hline 6 & IP CZD Warsaw & Y & Y & Y & Y & Y & Y \\
\hline 7 & UR Rzeszow & Y & Y & Y & Y & Y & Y \\
\hline 8 & UM Bialystok & Y & N & Y & Y & Y & Y \\
\hline 9 & WUM Warsaw & Y & N & Y & Y & Y & Y \\
\hline 10 & GUMED Gdansk & Y & Y & Y & Y & Y & Y \\
\hline 11 & PAIP Krakow & Y & Y & Y & Y & Y & Y \\
\hline
\end{tabular}

Y - Yes. $N-$ no.

Majority of the procedures (325) were performed under general anaesthesia, only 1 procedure was performed under conscious sedation, and 22 procedures under local anaesthesia.

In almost all of the centres the procedures were performed by a physician-endoscopist, assisted by another physician and a nurse specialising in endoscopy. During the procedures the patients were under continuous monitoring (Table II).

The most common complication of oesophageal dilation was bleeding during the procedure (95 cases in 347 procedures); nevertheless, this complication was never serious and it never required intervention. Serious complications were very rare, and only one case of oesophageal perforation was reported.

\section{Discussion}

The data on the management of oesophageal strictures in children obtained from 11 centres of paediatric endoscopy provide an overview of the treatment of this condition in Poland.

The aetiology of oesophageal strictures in children is different from that in adults. In adult patients the leading causes of oesophageal strictures are gastroesophageal reflux disease and oesophageal cancer [1, 2], and in children these are chemical oesophageal burns, esophagitis (reflux, eosinophilic or other types), and postoperative strictures. However, the relative proportions of these aetiological factors may vary depending on the region, local customs, and hazards [3-6]. Rare causes include oesophageal strictures caused by foreign bodies, infections, and achalasia.
Most frequent causes of oesophageal strictures reported by the Polish centres were postoperative strictures, followed by chemical oesophageal burns and postinflammatory strictures, which is consistent with some of the literature data $[7,8]$.

In our group of patients treated in 11 centres the children undergoing oesophageal dilation represented all age groups from neonates to 18 -year-old adolescents. However, a definite majority of procedures were performed in patients under 3 years of age. In the youngest age group postoperative strictures were observed, and this group was also at highest risk of accidental ingestion of irritants. Young age is also a risk factor for postinflammatory strictures. In infants the incidence of gastroesophageal reflux peaks in the fourth month of life, and thus postinflammatory strictures are most prevalent before the end of the first year of life [9].

Our data indicate that the majority of oesophageal dilations were performed with the use of rigid dilators ( $85 \%$ of procedures), and in the majority of the procedures a guidewire was used. Balloon dilators were used in only $15 \%$ of procedures. These proportions are most probably due to higher costs of balloon dilators (which are single-use only) and more expertise with the use of rigid dilators, which leads to more frequent use of this method. The available dilators are made of various materials and are of various sizes (including various lengths and diameters). They can be used both with and without a guidewire. Standard Savary-Gilliard dilators are available in diameters from 5 to $20 \mathrm{~mm}$; moreover, the smaller Tucker (from $12 \mathrm{~F} ; 4 \mathrm{~mm}$ ) and Hegar (from 9 F; 3 mm) dilators are available. Balloon dilators dedicated to oesophageal dilation are available 
in diameters from 6 to $20 \mathrm{~mm}$, and every available diameter usually allows for a dilation of another $3 \mathrm{~mm}$. Balloons available for dilation of cardia in patients with achalasia are only available in the diameters of 30, 35, or $40 \mathrm{~mm}$, so their use is possible exclusively in older children [5, 10-12]. Balloon oesophageal dilations have been performed for over 30 years [13]. From the very beginning the method was found to be safe and effective. This also includes numerous reports of its use in children, in whom the efficacy of this technique is from $76 \%$ to $100 \%$ and depends mainly on the aetiology of the stricture [14-16]. However, our data indicate that this method is still rarely used in Poland.

Oesophageal dilation can be performed both with the use of a gastroscope, and without it. However, in the Polish centres responding to our survey these procedures were always performed with the use of an endoscope. Endoscopy improves the safety of dilation. The oesophagus is inspected before qualification for the procedure. The endoscope is then used to introduce a guidewire or a balloon in the oesophagus. Endoscopy is useful in visual monitoring of balloon dilation and inspection of mucosa after the completed procedure.

Oesophageal dilation does not always require the use of a guidewire or fluoroscopic guidance. In Poland the most frequently used technique is the use of rigid guidewire dilators under fluoroscopic control. In our material, this technique was used in over $50 \%$ of the procedures. The use of fixed-diameter dilators without a guidewire was least common.

Oesophageal dilation in children usually requires more than one session. Our data from Polish centres indicate that one oesophageal dilation was sufficient only in $10 \%$ of children, and the vast majority of children (90\%) needed from 2 to $>6$ procedures (most commonly $2-3$ procedures), which is generally consistent with the data from literature [14-17]. In 13 children more than 6 procedures were necessary. In this group of patients the efficacy of oesophageal dilatation is limited and the strictures are persistent and recurrent. In such patients use of alternative endoscopic techniques [18, 19] or surgical oesophageal repair [20] should be considered.

Currently the procedures of oesophageal dilation in children are almost exclusively performed under general anaesthesia.

Endoscopic oesophageal dilation is associated with low risk of complications. The most frequent potential complication is oesophageal bleeding and the most serious is oesophageal perforation. The incidence of oesophageal perforations is $0.1-0.4 \%$, but there are some reports of much higher risk of perforation associated with balloon dilation, which may be over $20 \%$ [21]. In our material only one case of perforation out of 347 procedures was reported ( $0.28 \%)$. A delayed decision on oesophageal dilation probably increases the risk of perforation [22]. In children the risk of this complication may be higher because of more frequent strictures caused by chemical burns, which may extend over longer sections of the oesophagus.

Moreover, the risk of complications of anaesthesia, such as arrhythmia or bronchoconstriction following extubation, should be taken into account $[23,24]$.

\section{Conclusions}

Esophageal dilatation represent a small percentage of pediatric endoscopic procedures, the number of patients and the number of procedures performed in different endoscopic units significantly different from each other. The majority of children requiring dilation were patients up to 3 years of age with postoperative esophageal strictures. In the majority of the centers fixed-diameter wire-guided dilators were used, and in one third of the procedures these dilators were introduced without fluoroscopic guidance.

\section{Conflict of interest}

The authors declare no conflict of interest.

\section{References}

1. ASGE Guideline. Esophageal dilatation. Gastrointest Endosc 2006; 6: 755-60.

2. Lew RJ, Kochman ML. A review of endoscopic methods for esophageal dilatation. J Clin Gastroenterol 2002; 35: 117-26.

3. Romeo E, Foschia F, De Angelis P, et al. Endoscopic management of congenital esophageal stenosis. J Pediatr Surg 2011; 46: 838-41.

4. Kawahara H, Imura K, Makoto Y, et al. Clinical characteristics of congenital esophageal stenosis distal to associated esophageal atresia. Surgery 2000; 129: 29-38.

5. Khan KM. Endoscopic management of stricture in pediatrics. Techn Gastrointest Endosc 2013; 15: 25-31.

6. Lakhdarldrissi M, Khabbache K, Hida M. Esophageal endoscopic dilations. JPGN 2012; 54: 744-7.

7. SoutoBittecourt PF, DinizCarvalho S, Rodrigues Ferreira A, et al. Endoscopic dilatation of esophageal strictures in children and adolescents. J Pediatr 2006; 82: 127-31.

8. Dohil R, Hassal E. Esophageal stenosis in children. Gastrointest Endoscop Clin North Am 1998; 2: 369-87.

9. Nelson SP, Chen EH, Syniar GM at al. Prevalence of symptoms of gastroesophageal reflux during infancy. A pediatric practice-based survey. Pediatric practice research group. Arch Pediatr Adolesc Med 1997; 151: 569-72.

10. Chang CF, Kuo SP, Lin HC, et al. Endoscopic balloon dilatation for esophageal strictures in children younger than 6 years: experience in medical center. Pediatr Neonatal 2011; 52: 196-202.

11. ASGE status evaluation report. Tools for endoscopic stricture dilatation. Gastrointest Endosc 2013; 78: 391-404. 
12. ASGE and NASPGHAN guideline. Modifications in endoscopic practice for pediatric patients. Gastrointest Endosc 2014; 79: 699-710.

13. London RI, Trotman BW, DiMarino AJ, et al. Dilatation of severe esophageal strictures by an inflatable balloon catheter. Gastroenterology 1981; 80: 173-5.

14. Youn BJ, Kim WS, Cheon JE, et al. Balloon dilatation for corrosive esophageal strictures in children: radiologic an clinical outcomes. Korean J Radiol 2010; 11: 203-10.

15. Alshammari J, Quesnal S, Pierrot S, Couloigner V. Endoscopic balloon dilatation of oesophageal strictures in children. Int J Pediatr Othorhinolaryn 2011; 75: 1376-9.

16. Temiz A, Oguzkurt P, SerinEzer S, et al. Long-term management of corrosive esophageal stricture with balloon dilatation in children. Surg Endosc 2010; 24: 2287-92.

17. Pearson EG, Downey EC, Bernhart DC, et al. Reflux esophageal stricture - a review of 30 years' experience in children. J Pediatr Surg 2010; 45: 2356-60.

18. Woynarowski M, Dądalski M, Wojno V, et al. Novel, double-lumen removable stent to treat caustic esophageal stenosis. Endoscopy 2014; 46 Suppl. 1: E378-9.

19. Woynarowski M, Dądalski M, Wojno V, et al. Nasogastric tube as protection for recurrent oesophageal stricture: a case report. World J Gastroenterol 2014; 20: 4806-10.

20. Szymczak M, Łyszkowska M, Broniszczak D, Kamiński A. As sessment of the physical development of children after esophageal reconstruction 10 years follow-up. Pediatr Wsp 2010; 12: 109-12.

21. Lan LC, Wong KK, Lin SC, et al. Endoscopic balloon dilatation of esophageal strictures in infants and children: 17 years' experience and a literature review. J Pediatr Surg 2003; 38: 1712-5.

22. Contini S, Garatti M, Swarray Dean A, et al. Corrosive esophageal strictures in children: outcomes after timely or dilayed dilatation. Dig Liver Dis 2009; 41: 263-8.

23. Jacobsen $\mathrm{CH}$, Rasmussen $\mathrm{V}$, Rosenberg J, et al. Cardiovascular effects of esophageal dilatation under general anaesthesia. Dan Med Bull 1999; 46: 252-63.

24. Gercek A, Binnaz A, Dogan V, et al. Esophageal balloon dilatation in children: prospective analysis of hemodynamic changes and complications during general anesthesia. J Clin Anesth 2007; 19: 286-9.

Received: 19.04 .2015

Accepted: 18.05 .2015 